\title{
Industrial microgrids in Russia: regional systemic effects of its implementation
}

\author{
Elena Karanina $^{1, *}$, and Maksim Bortnikov ${ }^{1}$ \\ ${ }^{1}$ Vyatka State University, Moskovskaya St., 36, 610000 Kirov, Russia
}

\begin{abstract}
The concept of the "Energy strategy of Russia for the period up to 2035" implies a comprehensive structural transformation of the energy sector and its transition to a qualitatively new level through the use of digital technologies. One of the first steps in building a model of the Internet of energy in Russia may be the introduction of a mechanism for creating industrial microgrids, for which a draft resolution of the government of the Russian Federation has already been developed. The article considers the features of functioning of a new subject of electric power industry - active energy complexes, their conceptual, economic and legal features, and also developed a method for evaluating the system effects of their implementation.
\end{abstract}

\section{Prerequisites for the formation of new models of electric power industry in Russia}

The structure of the electric power industry in Russia was formed at the beginning of the last century, when the emphasis was placed on the full centralization and construction of large thermal and hydroelectric power plants, as the least expensive in terms of specific capex. The main part of the modern electric power complex was formed back in 19551990, when the energy industry developed at a faster pace [1].

However, since the time of the USSR, a fairly large number of economic and technological problems have accumulated, such as:

- low attractiveness for investment, especially in the retail electricity market;

- cross subsidization;

- lack of motivation for cost reduction for territorial network organizations (TNO) and large generation (from $25 \mathrm{MW}$ ) due to the cost structure of the tariffing;

- high costs of maintaining electrical networks remote from sources of generation

- a high proportion of depreciation of energy assets - in the electric power industry, about $40.2 \%$, and in the heat power industry $68 \%$;

- use of outdated technologies, as a result of low industry energy efficiency.

\footnotetext{
* Corresponding author: kafinanc@yandex.ru
} 
The Government of the Russian Federation needs to make a decision on the energy challenge - to stimulate the modernization of physically obsolete energy equipment, or to begin a phased transition to new energy practices of the 21 st century.

Energy transition is characterized by 3 directions ("3D"):

1. Decentralization- replacement of most inefficient and outdated stations with more energy-efficient and low-power TPPs (less than 25-50 MW);

2. Digitalization- transition to the Internet of energy, in the framework of which fast transactional transactions are possible to purchase eletric energy directly from the generator, bypassing sales companies; fast and stable intermachine interaction between power generation devices and consumer's / industrial equipment;

3. Decarbonization - the most environmentally friendly energy with the predominance of electric transport, an increase in the share of renewable energy sources, the rejection of coal generation, and so on.

At the moment, the most widespread in Russia are only distributed generation technologies, whose share in the total balance is estimated at $7 \%$, prevailing in the isolated territories of the UES of Russia. This indicator is seriously lagging behind foreign practices, for example, in Denmark (Fig. 1), an optimal energy model was created over 35 years, within which the unit capacities of large plants were reduced and dozens of mini TPPs (based on natural gas and biofuel) were created as well as renewable energy sources. This event, in addition to the emergence of a platform for intelligent energy, allowed reducing the loss of electric and thermal energy during transportation, as well as reducing the cost of maintaining the main networks.

1990

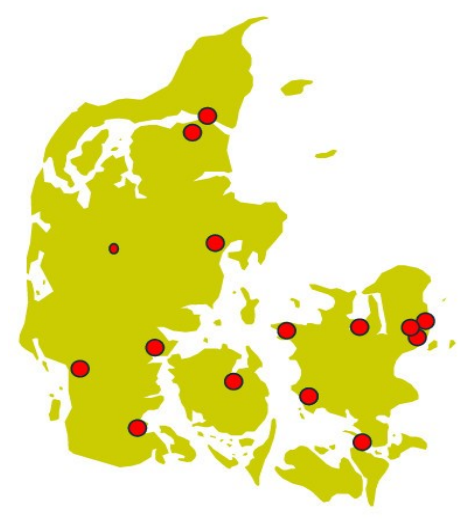

\section{4}

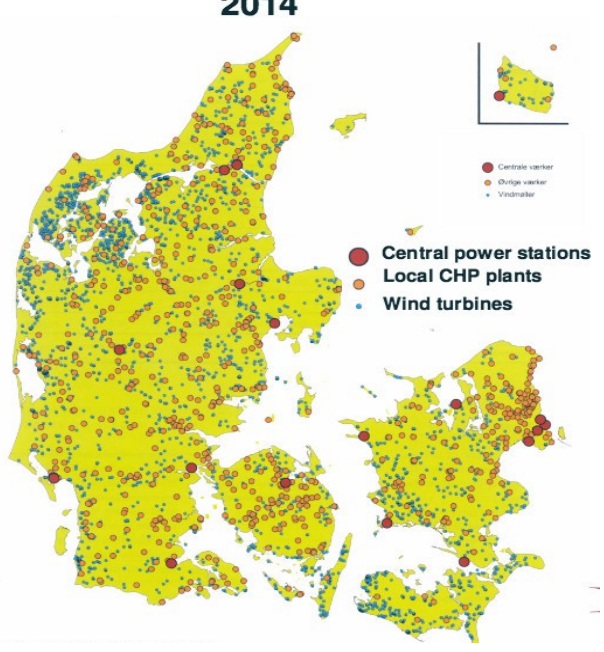

Fig. 1. Change in the structure of energy in Denmark due to the predominance of decentralization.

The decentralization paradigm mainly includes distributed energy and such subsystems as: industrial microgrid, demand response (DR), smart grid, electric energy storage systems and others.

DR is the only subsystem that is legally fixed in Russia. DR is the consumer's ability to reduce electricity consumption during peak hours (the highest prices on the wholesale market) or at a time when the reliability of the electricity network is at risk.

DR was applied only to large consumers, for example, UC Rusal, but in early 2019, an experiment on the participation of consumers of small unit capacity was approved. The experiment will be carried out in 2020, but it can already be argued that the UES of Russia will receive an additional effect from this event since the criterion for the selection of participants was to minimize the total amount of services rendered on energy efficiency 
starting from the minimum price of 1 ruble / MW to 566,666 rub / MW in a month, which is below the limit price levels.

As recent research literature suggests, the existing production structure of the territorial energy systems has a significant impact on the regional energy security. Energy security of the region constitutes an important issue that is key to the development of national economies [4].

\section{Features and rules of functioning of industrial microgrids}

The problems of cross-subsidization and the introduction of various financial mechanisms on the wholesale electricity market, for example, DPM RES, the tariff for energy efficiency for industrial consumers is growing much higher than the rate of inflation every year, which leads to an uncontrolled increase in mini thermal power plants, as well as illegal generation. In addition, it is planned to introduce a fee for the reserve of network capacity in Russia, which will entail additional annual expenses of large consumers for 342 billion rubles from mid-2020. Such unequal market conditions, when consumers without their own generation have a tariff of 5 rubles / $\mathrm{kWh}$ and higher, and with generation of about 2-2.5 rubles / $\mathrm{kWh}$, make an increasing number of consumers leave the energy system, shifting the costs to the remaining ones.

There are several ways out of this situation:

1. introducing prohibitive measures is not very attractive, as investment projects will be lost;

2. completely liberalize the market-it is critically dangerous, as it will lead to the destruction of small and medium-sized businesses that do not have enough funds to build small thermal power plants, increase accounts receivable, it is difficult to assess the tragedy of the situation;

3. to set special rules for a group of consumers creating industrial cells is promising, since groups are easier to manage and control, setting rules that are clear to all.

The working group of NTI «EnergyNet» proposes industrial microgrids (IMG) as such an industrial and energy cell.

According to the draft resolution of the Government of the Russian Federation, the IMG refers to an electric power production facility (power plant) operating within the UES of Russia and energy receiving devices of industrial enterprises and large commercial centers.

In addition to systemic effects of lower power limit for a group of consumers from the owner generation the opportunity to sell electricity within the IMG under free contracts, bypassing the "network tariff" which today makes it impossible for retail generation to sell electricity through direct contracts, reducing capacity factor have many mini TPP (if irregular daily schedule of electric energy consumption).

In general, the IMG scheme is shown in Fig. 2, from which it is seen that for the creation and functioning of this complex it is necessary to fulfill the following conditions:

1. Installation of controlled intelligent connection (CIC) IMG to regulate the flow of electrical energy within the complex;

2. IMG facilities are connected to the UES of Russia using a single connection, and not separately as in traditional architecture;

3. The allowed installed generation capacity is not more than $25 \mathrm{MW}$;

4. All objects inside the IMGare connected by electric grid facilities that do not belong to the TNO;

5. There are no consumers within the IMG related to the population, as well as consumers whose limitation of electricity consumption can lead to economic, environmental and social consequences;

6. No more than 2IMG per each constituent entity of the Russian Federation. 


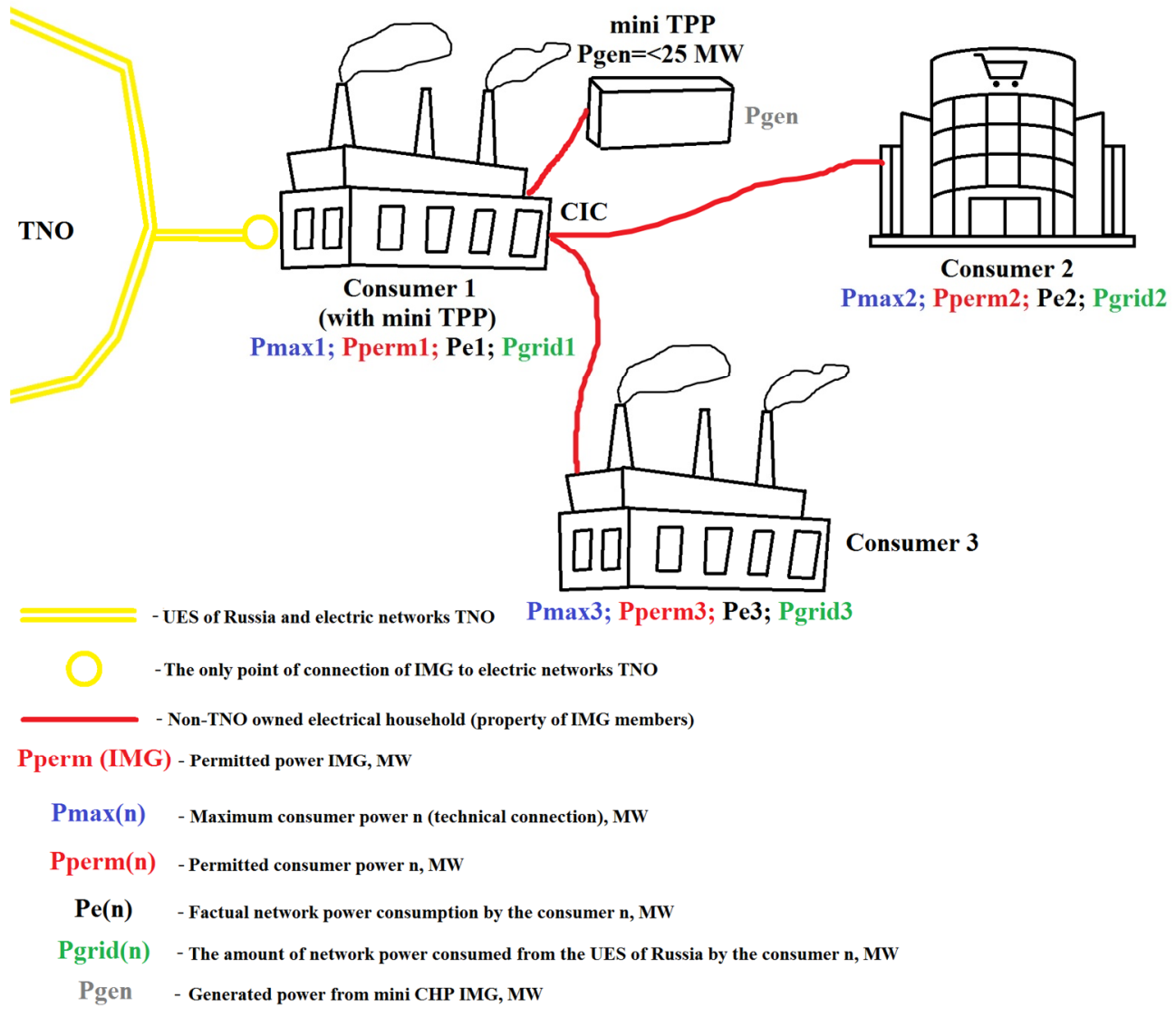

Fig. 2. IMG block diagram (developed by the author based on).

IMG subjects have the right to choose one of the payment options for electric power transmission services, while the obligations to pay for power supply services are determined by a two-part tariff (4, 6 price categories). Calculation options for IMG consumers are presented in the table 1 .

As can be seen from the table. 1 IMG model can be used both as a method of selling electric energy, bypassing the "network tariff", and as a way of an alternative possibility of obtaining the required amount of power at too high prices for technical connection to the UES of Russia in case of capacity increase by the enterprise, as well as in the absence of the necessary funds and competencies for the construction of its own generation. 
Table 1. Scheme for calculating the IMG and TNO for the transport of electric energy.

\begin{tabular}{|c|c|}
\hline Option 1 & Option2 \\
\hline Basicrulesofcalculation: & Basicrulesofcalculation: \\
\hline 1) For each Consumer define Pperm(n) with & 1) The power of the IMG is calculated based on \\
\hline $\operatorname{Pperm}(\mathrm{n})=>\operatorname{Pmax}(\mathrm{n})$ & Pperm $(\mathrm{IMG})=\sum(\operatorname{Pperm}(\mathrm{n} 1, \ldots, \mathrm{n}))$ \\
\hline $\begin{array}{l}\text { 2) Each consumer pays based on } \\
\min \{\operatorname{Pperm}(\mathrm{n}) ; \operatorname{Pe}(\mathrm{n})\}\end{array}$ & $\begin{array}{l}\text { 2) Each consumer pays for power taking into } \\
\text { account the generation of electric energy from a } \\
\text { mini TPP }\end{array}$ \\
\hline Example & Example \\
\hline Source data & Source data \\
\hline (Pmax; Pperm; Pe, Pgrid) & (Pmax; Pperm; Pe, Pgrid) \\
\hline Pperm $(\mathrm{IMG})=25 \mathrm{MW}$ & Pperm $(\mathrm{IMG})=25 \mathrm{MW}$ \\
\hline Pgen $=2 \mathrm{MW}$ & Pgen $=2 \mathrm{MW}$ \\
\hline Consumer $1: 10 ; 10 ; 14 ; 10$ & Consumer $1: 10 ; 10 ; 14 ; 13$ \\
\hline Consumer 2: 10;10;6; 6 & Consumer 2: 10;10;6;5,5 \\
\hline Consumer $3: 5 ; 5 ; 2 ; 2$ & Consumer $3: 5 ; 5 ; 2 ; 1,5$ \\
\hline Calculation & Calculation \\
\hline $\begin{array}{l}\text { In total, the IMG facilities consumed } 22 \mathrm{MW} \\
\text { of network power (while } 2 \mathrm{MW} \text { was consumed } \\
\text { from the IMG's own generation). Subject to the } \\
\text { "2)" rule, } 18 \mathrm{MW} \text { is subject to payment. }\end{array}$ & $\begin{array}{l}\text { The total consumption of IMG is also } 22 \mathrm{MW} \text {. } \\
\text { However, the actual consumption minus } \\
\text { generation is always subject to payment. In this } \\
\text { example, this is } 20 \mathrm{MW} \text {. }\end{array}$ \\
\hline \multicolumn{2}{|c|}{$\begin{array}{l}\text { ! In [5], there is no mechanism for changing the payment method, so you must choose it } \\
\text { individually for each energy cluster, taking into account the possibility of the TNO to initiate the } \\
\text { elimination of the IMG when the Pperm (IMG) is exceeded. }\end{array}$} \\
\hline
\end{tabular}

\section{Analysis of system effects from the creation of IMG}

When creating the IMG it is important to take into account not only local commercial efficiency for IMG facilities, but also industry and system effects.

\subsection{Improving the energy security of the region.}

The energy security of the region is understood as a whole pool of issues, starting from the degree of infrastructure development, ending with the availability of certain resources, as well as the possibility of their uninterrupted consumption.

In each specific case, the quantitative effect of entering the IMG is different (depending on the capacity, territorial location, type of generation, and so on), but it is possible to determine the qualitative dynamics of changes in indicators. According to [9], there are 7 aggregate groups (blocks) of indicative indicators:

1. provision of electric and thermal energy;

2. providing fuel;

3. structural-mode block;

4. reproduction of fixed assets in the energy sector;

5. environmental;

6. financial and economic;

7. energy saving and energy efficiency.

The introduction of IMG will have a positive impact on the following indicators:

1. share of own sources in the electricity balance in the territory;

2. share of installed capacity of the largest power plant;

3 . the ratio of the available capacity of power plants to the maximum electrical load of consumers; 
4. the ratio of the amount of available capacity of power plants and the capacity of intersystem connections of the territory with adjacent ones to the maximum electric load of consumers;

5. the degree of depreciation of fixed assets for electric power companies;

6 . energy intensity of the gross regional product (GRP);

7. the relative value of electricity losses in electric networks;

8. the specific consumption of conventional fuel for the production of heat (when the IMG operates as a source of heat power in the municipal household with an increase in the share of cogeneration-described below).

The introduction of IMG may negatively affect the following indicators:

1. the specific consumption of conventional fuel for electricity production (small generation is inferior to large, but compensates for this disadvantage with low losses in the electric networks);

2. emissions of harmful substances into the atmosphere from electricity enterprises per unit area of territories (for example, in subjects with a high predominance of the share of RESlarge HPPs).

\subsection{Reduction of electrical energy losses in distribution networks}

In foreign countries where distributed energy has become the most widespread, there is a large number of scientific studies that indicate the effect of reducing energy losses during transportation in the case of using a mini TPP. However, special attention should be paid to the method of modeling the place of implementation of this object, for example [10], since the effect of this event in different places of its localization is different.

In General, the reduction in the cost of compensation for technological losses (load and idle) of electricity when it is transmitted through electric networks after entering, the IMG can be estimated using the formula:

$$
E_{e e}^{t e c}=\left(W_{f a c t}^{t e c}-W_{I M G}^{t e c}\right) \times \tau_{\text {grid }}^{e e}
$$

where $W_{\text {fact }}^{\text {tec }}$-actual loss of electrical energy before entering the IMG, MWh;

$W_{I M G}^{\text {tec }}$ - loss of electrical energy after entering the IMG due to a decrease in Pmax and Pe between Consumers within the IMG due to their own generation source, MWh;

$\tau_{\text {grid }}^{e e}-$ tariff for payment of technological expenses (losses) in electric networks, $\mathrm{RUB} / \mathrm{MWh}$

\subsection{Reduction of forced investments in the development of distribution networks to connect new consumers}

With the introduction of IMC in the power supply system, several effects can be achieved at once in terms of the need to build distribution networks for new subscribers:

When the total allowed capacity is reduced to the level of the Pperm(IMG), a certain amount of power appears, which can be redistributed from the reserved to the" real " consumption;

With the advent of free capacity partially offset the need to invest in distribution network, reduction of capital costs is determined by project, but you can consider this effect when using large values for the construction of power lines and transformer substations according to the following formula:

$$
E c_{\text {grid }}^{c c}=k_{o} \times l_{o}+k_{c} \times l_{c}+k_{t s} \times n_{t s}
$$


where $k_{o}, k_{c}, k_{t s}$ - specific capital investments in the construction of $1 \mathrm{~km}$ of overhead and cable lines $(\mathrm{RUB} / \mathrm{km})$, as well as in the construction of one substation of available capacity, respectively (RUB/PC);

$l_{o}, l_{c}$ - the length of air and cable lines, respectively, from the previous power source to the consumer, $\mathrm{km}$;

$n_{t s}$ - the number of substations required to connect new consumers and replaced by IMG, PCs.

In addition, it is necessary to take into account the monthly effect that occurs when the declared network capacity decreases, which can be determined by the formula:

$$
E_{m}^{t e c}=\left(P_{\max }^{1}+P_{\max }^{2}+\cdots+P_{\max }^{n}-\operatorname{Pperm}(I M G)\right) \times \tau_{\text {grid }}^{c, e e}
$$

where $P_{\max }^{n}-$ maximum capacity (by technical connection) of each $\mathrm{n}$ consumer inside the IMG, before the creation of the IMG, MW;

Pperm (IMG) - maximum permitted power for IMG, MW;

$\tau_{\text {grid }}^{c, e e}$ - tariff for maintenance of electric networks RUB/MW.

This effect applies not only to IMG participants, but also partially to TNO (to the energy system as a whole), which are required to contain the full declared capacity of the power grid complex of subscribers today, while receiving payment only for actual consumption. In the case of IMG, both the actual and declared network capacity are reduced.

\subsection{The emergence of a new modernized energy infrastructure for use as a heat source}

As a rule, large CHP plants are located in large cities, while small ones use boiler rooms with high equipment wear.

The organization of heat supply from the IMG will allow solving several municipal and regional problems at once, namely:

1. Reduce / keep the tariff for heat energy for the population at the same level, since the average tariff for thermal power plants is $60-80 \%$ lower than for boiler houses. For comparison, according to the regional tariff service in the Kirov region, the tariff of JSC "KHC" for thermal energy in the city of Kirov is 1750 rubles/Gcal, in the Kumensky district the tariff reaches 5000 rubles/Gcal, and the average for the region is about 3000 rubles/Gcal;

2. Fulfill the requirement for the regions to build and reconstruct thermal energy production facilities with a capacity of more than $5 \mathrm{Gcal} /$ hour for a combined cycle of both thermal and electric energy.

In General, the economic effect of replacing not the most efficient heat generation in boiler can be estimated using the formula:

$$
E c_{\mathrm{he}}^{\text {boil }}=\left(\tau_{\mathrm{h} e}^{\prime}-\tau_{\mathrm{h} e}^{\prime \prime}\right) \times Q_{\mathrm{he}}^{\text {year }}
$$

where $Q_{\text {he }}^{\text {year }}$-annual release of heat energy to Consumers, Gcal;

$\tau_{\mathrm{h} e}^{\prime}$ - tariff for heat energy from the boiler house for the current regulatory period, RUB/Gcal;

$\tau_{\mathrm{h} e}^{\prime \prime}$ - the tariff for heat energy from the IMG mini CHP, taking into account capital expenditures for the modernization of the heat supply system calculated using the «alternative boiler house method», RUB/Gcal.

As a result, the system effect of the introduction of UEC in the regional power system can be estimated using the following indicators: 
- Netpresentvalue (NPV):

$$
N P V=\sum_{t=1}^{T} \frac{\left(R_{t}-C_{t}-K_{t}+E_{e e}^{t e c}+E c_{g r i d}^{c c}+E_{m}^{t e c}+E c_{\mathrm{he}}^{b o i l}\right)}{(1+E)^{t}}
$$

where $N P V$ - net present value of the IMG, RUB;

$R_{t}$ - revenue from electricity sales between IMG entities (including the economic effect of electricity consumption relative to tariffs on the retail electricity market and capacity for the owner of IMG generating equipment) and the local heat energy market in year $t$ of the investment period T, RUB;

$C_{t}$-the cost of production of electricity and heat excluding depreciation, RUB;

$K_{t}$ - total capital investment in the project of creation of the IMG, RUB;

$E$ - discount rate.

- The profitability index of the IMG, taking into account systemic effects:

$$
P I=\sum_{t=1}^{T} \frac{\left(R_{t}-C_{t}-K_{t}+E_{e e}^{t e c}+E c_{g r i d}^{c c}+E_{m}^{t e c}+E c_{\mathrm{he}}^{\text {boil }}\right) \times(1+E)^{-t}}{K_{t} \times(1+E)^{-t}}
$$

$P I$ - the profitability index of the IMG, rel. ed.

The effectiveness of creating your own generation at the enterprise has been proven by multiple cases. The creation of IMG from the investor's point of view can be evaluated using the same logic - the NPV is positive, so the project is effective. However, for an investor, a project with a large NPV will be preferable.

Another important indicator is the internal rate of return (IRR), which is determined by solving the equation using the iterative method (for $\mathrm{NPV}=0$ ):

$$
\sum_{t=1}^{T} \frac{\left(R_{t}-C_{t}-K_{t}+E_{e e}^{t e c}+E c_{g r i d}^{c c}+E_{m}^{t e c}+E c_{\mathrm{he} e}^{\text {boil }}\right)}{(1+E)^{t}}=0
$$

In the end, according to the IRR indicator, the investor will decide to create a IMG only after comparing the values of the internal rate of return and observing the following inequality::

$$
E \leq E_{i n t}^{\prime} \leq E_{\text {int }}^{\prime \prime}
$$

where $E_{\text {int }}^{\prime}$ - internal rate of return for creating your own generation in the enterprise;

$E_{i n t}^{\prime \prime}$ - internal rate of return for creating IMG.

The creation of industrial microgrids is a new energy model for the electric power and capacity market in Russia and has several significant advantages both for the investment attractiveness of local places in the regions and for a new socio-economic tool for attracting people to single-industry towns by reducing the cost of utilities. For IMG to appear in the regions, the possibility of using PPP mechanisms to co-Finance these projects and reduce investment risks should be considered. In addition, test projects for the creation of IMG stimulate regions to create/revive regional target programs for the development of small energy complex.

The article substantiates the need to prepare for the transition to a new model of the energy market and such a tool as the IMG, develops an express methodology and provides an example of calculating the economic efficiency of this project. In addition, the following system and industry effects were identified and taken into account: an increase in regional energy security (improvements in a number of indicators), a decrease in electricity losses during transmission of electric energy, the appearance of free network capacity and a decrease in forced investments in the construction of distributed networks, and the method of appearance of a new investment tool in the local heat market. 


\section{References}

1. M.V. Kakhalnikov, E.V. Sukhareva, N.D. Rogalev, Economic Sciences 10, (2018). DOI: $10.14451 / 1.1675$

2. A. Omerovic, H. Vefsnmo, G. Erdogan, O. Gjerde, E. Gramme, S. Simonsen (2019). DOI:10.5220/0007697800390051.

3. F. Song, M. Irving (2007). DOI:10.1109/UPEC.2007.4468917.

4. E. Lisin, N. Rogalev, and P. Okley, Terra Economicus 17, 2 (2019). DOI: 10.23683/2073-6606-2019-17-2-96-111

5. R.R. Labastida, P. Asmus, B. Feldman, Defining, Distributed Energy Resources Management Systems (2018)

6. P. Saundry, Energy, Sustainability and Society 9 (2019) DOI:10.1186/s13705-0180178-8.

7. M.S. Razi, and Y. Ali, Environment Systems and Decisions (2018). DOI:10.1007/s10669-018-9713-6.

8. J. Hu, R. Harmsen, W. Crijns-Graus, and E. Worrell, Renewable Energy, Elsevier 121, C (2018) DOI: $10.1016 /$ j.renene.2018.01.092

9. E.P. Korsak, Energetika. Proa CIS Higher Educ. Inst. and Power Eng. Assoc. 62, 4, (2019). DOI:10.21122/1029-7448-2018-62-4-388-398

10. Q. Kejun, Z. Chengke, A. Malcolm, Y. Yue, International journal of electrical power \& energy systems (2011) 